\title{
PHÂN TÍCH TÁC ĐỘNG CỦA HÔI NHẬP TÀI CHÍNH ĐẾN TĂNG TRƯỞNG KINH TẾ TẠI VIẸTT NAM
}

\author{
Phan Khoa Cương, Trần Thị Bích Ngọc, Phạm Quốc Khang
}

March 14, 2016 


\section{GIỚI THIÊUU THÔNG TIN}

Ngày gửi bài: $\quad$ 14/03/2016

Tên tác giả:

1. TS Phan Khoa Cương

2. TS Trần Thị Bích Ngọc

3. ThS Phạm Quốc Khang

Đơn vị công tác:

Khoa Tài chính - Ngân hàng

Trường Đại học Kinh tế

Đại học Huế

Thông tin liên lạc:

TS Phan Khoa Cương

Email: pkcuong@hce.edu.vn

Điện thoại: 0903511268

TS Trần Thị Bích Ngọc

Email: ttbngoc@hce.edu.vn

Điện thoại: 0905492373

\section{ThS Phạm Quốc Khang}

Email: pqkhang@hce.edu.vn

Điện thoại: 0972995959

\section{Lĩnh vực nghiên cứu: $\quad$ Tài chính - Ngân hàng}

Tên bài viết: Phân tích tác động của hội nhập tài chính đến tăng trưởng kinh tế tại Việt Nam

Chủ đề: Tài chính - Kế toán

Ngôn ngữ: Tiếng Việt

Số từ của bài viết: 5796

Việt Nam đang ngày càng hội nhập sâu và rộng vào nền kinh tế thế giới, trong đó có hội nhập tài chính. Về lý thuyết, hội nhập tài chính sẽ có tác động tích cực đến tăng trưởng kinh tế của một quốc gia. Tuy nhiên, theo hiểu biết của nhóm tác giả, chưa có nghiên cứu thực nghiệm nào được tiến hành nhằm phân tích tác động của hội nhập tài chính đến tăng trưởng kinh tế tại Việt Nam. Vì vậy, việc thực hiện nghiên cứu này có tính cấp thiết và có giá trị thực tiễn cao. 


\section{PHÂN TÍCH TÁC ĐỘNG CỦA HÔI NHẬP TÀI CHÍNH ĐẾN TĂNG TRƯởNG KINH TẾ TẠI VIỆT NAM}

\section{Tóm tắt}

Bài báo nghiên cứu tác động của hội nhập tài chính đến tăng trưởng kinh tế của Việt Nam giai đoạn 1995-2014. Nghiên cứu lựa chọn biến đầu tư trực tiếp nước ngoài/GDP để đại diện cho hội nhập tài chính và GDP bình quân đầu người cho tăng trưởng kinh tế. Ngoài ra, độ mở thương mại, đầu tư trong nền kinh tế/GDP, tín dụng cho khu vực tư nhân cũng được đưa vào mô hình nghiên cứu. Với việc sử dụng mô hình vectơ hiệu chỉnh sai số (VECM) cho số liệu năm, kết quả nghiên cứu cho thấy cả trong ngắn hạn và dài hạn, hội nhập tài chính đều tác động tích cực đến tăng trưởng kinh tế. Trong dài hạn, tín dụng cho khu vực tư nhân tác động thuận chiều và tỷ số đầu tư trong nền kinh tế/GDP tác động nghịch chiều đến tăng trưởng kinh tế. Trong khi đó, trong ngắn hạn, ngoài hội nhập tài chính, chỉ có tín dụng cho khu vực tư nhân có tác động đến tăng trưởng kinh tế và tác động này mang tính tích cực. Ngoài ra, kết quả nghiên cứu cũng chi ra rằng nếu nền kinh tế bị lệch khỏi mối quan hệ dài hạn thì cần rất nhiều thời gian để quay trở về trạng thái cân bằng.

Từ khóa: Hội nhập tài chính, tăng trưởng kinh tế, mô hình vecto hiệu chỉnh sai số, Việt Nam.

\section{AN ANALYSIS OF THE IMPACT OF FINANCIAL INTEGRATION ON ECONOMIC GROWTH IN VIETNAM}

Abstract: This paper aimes to investigate the impact of financial integration on economic growth of Vietnam during the period 1995-2014. This research chooses net foreign direct investment inflow to GDP as proxy for financial integration and GDP per capita as proxy for economic growth. Furthermore, trade openness, investment ratio and credit to private sector are also included in the model. By using the vector error correction model (VECM) for annual data, the research results show that in the short run as well as in the long run, financial integration affects positively on economic growth. In the long run, credit to private sector has positive impact and investment ratio has negative impact on economic growth. Meanwhile, in the short run, besides financial integration, only credit to private secteur influences economic growth positively. Moreover, the results also show that if the economy deviates from the long run trend, it will need a lot of time to return back to equilibrium state.

Keywords: Financial integration, economic growth, Vector Error Correction Model, Vietnam

\section{1. ĐẶT VẤN Đî̀}

Việt Nam đang trong quá trình hội nhập kinh tế quốc tế ngày càng sâu và rộng. Trong 20 năm qua, Việt Nam đã là trở thành thành viên của rất nhiều tổ chức kinh tế như ASEAN (1995), ASEM (1996), APEC (1998), WTO (2006), TPP (2015). Việt Nam đã mở rộng mối quan hệ thương mại, tài chính với ngày càng nhiều quốc gia hơn. Hiện nay, Việt Nam đang tích cực đàm phán các hiệp định thương mại tự do (FTA) với nhiều đối tác khác như Liên minh Châu Âu, Khối thương mại tự do Châu Âu... Bên cạnh đó, Cộng đồng kinh tế ASEAN (AEC) đã 
được hình thành vào cuối năm 2015 mà Việt Nam là một thành viên đầy đủ. Đây thực sự sẽ là cơ hội lớn để Việt Nam mở rộng giao thương và tiếp cận thị trường rộng lớn, thu hút đầu tư nước ngoài, cải cách thể chế, hiện đại hóa nền kinh tế bắt nhịp cùng với xu thế và trình độ phát triển của khu vực và thế giới. Đặc biệt, với việc hình thành $\mathrm{AEC}$ sẽ đem lại cơ hội cho sự phát triển thị trường tài chính khi việc tự do hóa luồng hàng hóa dịch vụ, tự do hóa dòng chu chuyển đầu tư và tự do hóa dòng vốn được diễn ra trong nội bộ ASEAN.

Quá trình hội nhập tài chính cũng là một tất yếu đi kèm với quá trình hội nhập quốc tế. Việt Nam đã bắt đầu thực hiện lộ trình hội nhập tài chính từ những năm 90 của thế kỷ XX, nhưng diễn ra chậm trong thời gian đầu này; quá trình hội nhập chỉ thật sự cởi mở hơn khi Việt Nam công nhận khu vực vốn đầu tư nước ngoài là một trong 6 thành phần kinh tế tại Đại hội Đảng lần thứ IX năm 2001. Kết quả là kể từ đó Việt Nam liên tục đạt tốc độ tăng trưởng kinh tế cao, đặc biệt trong giai đoạn 2000 - 2007, tốc độ tăng trưởng luôn ở mức trên 6,5\%; đạt đỉnh vào năm 2007 ở mức 8,5\% (Theo Tổng cục Thống kê).

Tuy nhiên, trong quá trình hội nhập tài chính, Việt Nam cũng sẽ phải đối mặt với không ít khó khăn, thách thức như năng lực cạnh tranh của hệ thống ngân hàng thương mại, năng lực quản trị của lãnh đạo ngân hàng, sự di chuyển của các dòng vốn, tỷ giá bị tác động... Ngoài ra, Việt Nam đối mặt với các tác động xã hội đến từ quá trình hội nhập như ô nhiễm môi trường, phân hóa giàu nghèo, biến đổi khí hậu...Trước thực tế này đòi hỏi Việt Nam cần phải có những chiến lược và chính sách hợp lý để tận dụng cơ hội và vượt qua thách thức trong quá trình hội nhập kinh tế.

Trong lý thuyết kinh tế, các thảo luận về mối quan hệ giữa hội nhập tài chính và tăng trưởng kinh tế được rất nhiều nhà kinh tế, học giả đề cập đến trong các nghiên cứu của mình. Tồn tại một mối tương quan tích cực và mạnh mẽ giữa hội nhập tài chính với tăng trưởng kinh tế được tìm thấy trong hầu hết kết quả của các nghiên cứu. Vì vậy, các chính sách hội nhập tài chính có ý nghĩa quan trọng trong cải thiện hiệu quả đầu tư của nền kinh tế, thúc đẩy tăng trưởng kinh tế. Nhiều bằng chứng thực nghiệm cũng đã chứng minh rằng, quốc gia có chính sách tài chính tự do hơn sẽ đạt được mức tăng trưởng cao hơn (nghiên cứu của Levine, 1997; của McKinnon và Shaw, 1973).

\section{TỔNG QUAN VỀ HộI NHẬP TÀI CHÍNH VÀ TĂNG TRƯỞNG KINH TẾ}

\subsection{Hội nhập tài chính}

Trong tài chính quốc tế, các học giả vẫn chưa có một khái niệm chuẩn hóa cho thuật ngữ hội nhập tài chính. Hội nhập tài chính là một phạm trù phổ biến được nhắc đến cùng với một số thuật ngữ như: độ mở tài chính, toàn cầu hóa tài chính, tự do hóa tài chính, tự do hóa tài khoản vốn... Theo Edison và cộng sự (2002), hội nhập tài chính quốc tế thể hiện ở mức độ giới hạn của quốc gia trong giao dịch tài chính qua biên giới. Theo Schmukler và cộng sự (2001), toàn cầu hóa tài chính là sự hội nhập của hệ thống tài chính trong nội bộ quốc gia với thị trường tài chính và tổ chức tài chính của thế giới. Prasad và cộng sự (2003) lại cho rằng toàn cầu hóa tài chính và hội nhập tài chính là hai khái niệm khác nhau hoàn toàn; toàn cầu hóa tài chính là khái niệm tổng hợp liên quan đến liên kết toàn cầu thông qua dòng chảy tài 
chính xuyên biên giới; hội nhập tài chính liên quan đến tất cả mối liên kết của cá nhân quốc gia với thị trường tài chính quốc tế. Nhìn chung, hội nhập tài chính thường đòi hỏi chính phủ của quốc gia phải xóa bỏ quản lý hành chính hoặc xóa bỏ các quy định, rào cản, phân biệt đối xử về thuế hoặc pháp lý giữa người cung cấp dịch vụ tài chính trong nước với ngoài nước (Von Furstenberg, 1998).

Tóm lại, hội nhập tài chính không chỉ là việc xóa bỏ quy định pháp lý hay quản lý hành chính đối với dịch chuyển dòng vốn quốc tế. Mà hội nhập tài chính còn đòi hỏi một thể chế giúp cho thị trường tài chính quốc tế được phát triển cạnh tranh và an toàn. Khi hội nhập tài chính đạt đến trình độ cao thì thị trường tài chính trong nước sẽ trở thành một bộ phận của thị trường tài chính thế giới. Biến động của lãi suất, tiết kiệm, đầu tư lúc đó sẽ tương đồng với thị trường thế giới (Meschach, 2007).

\subsection{Lợi ích của hội nhập tài chính}

Nếu một quốc gia đóng cửa với bên ngoài, không có thương mại, không có dịch chuyển dòng tài chính từ bên ngoài; nguồn tài trợ cho đầu tư của quốc gia phụ thuộc hoàn toàn vào tiết kiệm trong nước. Lúc đó, đầu tư và tiết kiệm của quốc gia sẽ cân bằng thông qua lãi suất nội địa, trong mối tương quan giữa lãi suất tiết kiệm và lãi suất cho vay. Nguồn lực của quốc gia sẽ không được sử dụng hiệu quả vì thiếu vốn do nguồn tiết kiệm nội địa không đủ cung cấp. Hạn chế trên sẽ được khắc phục khi hội nhập tài chính, dòng vốn chảy đến nơi cần; đặc biệt dòng vốn ngoại có vai trò quan trọng với các nước đang phát triển. Việc khai thác hiệu quả dòng vốn nước ngoài là một nhân tố đem lại thành công cho tăng trưởng của các nước đang phát triển. Theo Reisen (1996, trích dẫn từ Ngân hàng Thế giới 1997), nếu dòng vốn nước ngoài chảy vào chiếm khoảng $3-4 \%$ GDP thì dựa trên tỷ trọng vốn và tỷ trọng vốn trên sản lượng, tốc độ tăng trưởng của quốc gia sẽ tăng khoảng nửa điểm phần trăm. Tuy nhiên, yếu tố quyết định cho tăng trưởng không phải là giá trị của dòng vốn mà "chất lượng" đầu tư mới là yếu tố quyết định (Ngân hàng Thế giới, 1997).

Bên cạnh đó, hệ thống tài chính của quốc gia sẽ được thúc đẩy phát triển theo chiều sâu đi sau quá trình hội nhập kinh tế; nó có tác động tích cực đến tăng trưởng nhờ vào việc sử dụng nguồn lực hiệu quả hơn. Đến lượt tăng trưởng lại dẫn đến tài chính phát triển sâu hơn. Sự tham gia của nhà đầu tư nước ngoài trên thị trường chứng khoán sẽ làm tăng thanh khoản cho thị trường, thúc đẩy thị trường phát triển. Đồng thời, các định chế tài chính quốc tế sẽ du nhập công cụ tài chính mới, tăng tính cạnh tranh hơn trên thị trường. Bằng chứng thực nghiệm từ nghiên cứu của Singh (1994, trích dẫn từ Ngân hàng Thế giới, 1997) cho thấy nguồn vốn bên ngoài quan trọng với nước đang phát triển hơn là nước phát triển. Dòng vốn bên ngoài chảy vào nhiều giúp sự chuyển hóa vốn và quay vòng vốn trên thị trường chứng khoán nhiều hơn so với các nước có dòng vốn vào thấp.

Quốc gia có sự hội nhập tài chính sẽ thụ hưởng được ngoại tác tích cực từ dòng vốn đầu tư trực tiếp nước ngoài (FDI). FDI đem lại ba ngoại tác cho nền kinh tế của quốc gia có FDI chảy vào. Thứ nhất, FDI chảy vào quốc gia không chỉ bổ sung vốn đầu tư mà còn có tác dụng thúc đẩy đầu tư trong nước tham gia, gia tăng tổng đầu tư trong nước. Một đôla FDI chảy vào 
quốc gia thì tăng thêm tổng đầu tư trong nước nhiều hơn một đôla. Thứ hai, FDI thúc đẩy cạnh tranh giữa các doanh nghiệp trong nước và nước ngoài về vốn, nhân lực, công nghệ... Nếu các doanh nghiệp trong nước không đầu tư thì đầu tư FDI thay thế cũng sẽ trở nên hiệu quả hơn. Thứ ba, FDI giúp nâng cao trình độ tay nghề cho công nhân, trình độ quản lý, thái độ, tác phong làm việc của doanh nghiệp FDI. Ngoài ra, FDI còn thúc đẩy cho xu hướng hợp tác công tư (PPP) trong đầu tư cơ sở hạ tầng, phát triển khu công nghiệp. FDI còn tạo ra áp lực cải cách đối với các định chế trong nước, cải cách thể chế trong khu vực công.

Tóm lại, hội nhập tài chính chứa đựng tiềm năng tăng trưởng cho một quốc gia. Hội nhập tài chính không chỉ có những tác động trực tiếp đến tăng trưởng mà thông qua hội nhập tài chính còn tạo ra những ngoại tác tích cực đến tăng trưởng.

\subsection{Các nghiên cứu về mối quan hệ giữa hội nhập tài chính và tăng trưởng kinh tế}

Mối quan hệ giữa hội nhập tài chính và tăng trưởng kinh tế nhận được sự quan tâm của rất nhiều học giả kinh tế. Đã có nhiều nghiên cứu thực nghiệm đã được tiến hành nhằm kiểm định mối tương quan giữa hội nhập tài chính với tăng trưởng kinh tế.

\subsubsection{Nghiên cứu quốc tế}

Mougani (2012) nghiên cứu tác động của hội nhập tài chính thế giới đến nền kinh tế và sự biến động vĩ mô của các nước Châu Phi. Kết quả cho thấy tác động của dòng vốn bên ngoài đến tăng trưởng phụ thuộc chủ yếu vào các điều kiện ban đầu và các chính sách nhằm ổn định đầu tư nước ngoài, tăng đầu tư nội địa, năng suất và thương mại, phát triển hệ thống tài chính nội địa, tăng độ mở thương mại và các hành động khác nhằm kích thích tăng trưởng và giảm đói nghèo.

Nghiên cứu của Ovans (2013) sử dụng mô hình hồi quy dữ liệu bảng để phân tích tác động của hội nhập tài chính và độ sâu tài chính đến tăng trưởng kinh tế của các nước vùng hạ sa mạc Sahara, Châu Phi. Trong nghiên cứu này, tác giả sử dụng tỷ số Đầu tư nước ngoài/GDP làm đại diện cho hội nhập tài chính, tỷ số tổng nguồn vốn/GDP đại diện cho đầu tư và Tín dụng nội địa/GDP đại diện cho độ sâu tài chính. Kết quả cho thấy hội nhập tài chính và độ sâu tài chính tác động tích cực đến tăng trưởng kinh tế của các quốc gia này.

Bên cạnh đó, nhiều nghiên cứu về phát triển tài chính và tăng trưởng kinh tế cũng được thực hiện. Nghiên cứu điển hình, cơ bản nhất về mối quan hệ giữa phát triển tài chính và tăng trưởng là nghiên cứu của King và Levine (1993), dựa trên mẫu nghiên cứu 80 quốc gia trong giai đoạn 1960 - 1989. King và Levine sử dụng 4 thước đo đại diện cho phát triển tài chính: (i) tỷ lệ cung tiền M3/GDP hoặc có thể thay thế bằng M2/GDP; (ii) tỷ lệ tài sản ngân hàng trên tài sản hệ thống ngân hàng + tài sản ngân hàng trung ương; (iii) tỷ lệ tín dụng khu vực tư nhân trên tổng tín dụng nội địa; (iv) tỷ lệ tín dụng tư nhân trên GDP. Kết quả nghiên cứu cho thấy tồn tại mối tương quan chặt chẽ và thuận chiều giữa phát triển tài chính và tăng trưởng kinh tế, tích lũy vốn vật chất, và cải thiện hiệu quả kinh tế. Tài chính phát triển sẽ dẫn đến tăng trưởng kinh tế nhanh hơn.

Nghiên cứu của Jahfer và Inoue (2014) sử dụng mô hình VECM để phân tích mối liên hệ giữa phát triển tài chính và tăng trưởng kinh tế bằng dữ liệu quý của Nhật Bản trong giai đoạn 
1957 - 2011. Các tác giả sử dụng 6 thang đo để làm chỉ báo phát triển tài chính: (i) tỷ số cung tiền M2/GDP danh nghĩa- đây là thang đo tiêu chuẩn cho sự phát triển tài chính (nghiên cứu của Calderon \& Liu, 2003; King và Levine, 1993); (ii) tín dụng nội địa/GDP; (iii) tín dụng cho khu vực tư nhân/GDP danh nghĩa (nghiên cứu của Beck, Levine \& Loayza, 2000; Demetriades \& Hussein, 1996); (iv) Dư nợ cho vay ngân hàng nội địa/GDP danh nghĩa; (v) vay ngắn và dài hạn của doanh nghiệp từ các định chế tài chính/giá trị gia tăng (SLBFIVA); (vi) giá trị vốn hóa thị trường/GDP danh nghĩa. Kết quả của Jahfer và Inoue cũng chỉ ra phát triển tài chính, phát triển thị trường vốn có tác động tích cực đến tăng trưởng kinh tế.

\subsubsection{Nghiên cứu ở Việt Nam}

Tại Việt Nam, chưa có nghiên cứu nào được tiến hành nhằm phân tích tác động của hội nhập tài chính đến tăng trưởng kinh tế. Tuy vậy, đã có một số nghiên cứu liên quan như nghiên cứu của Vương Quân Hoàng, Trần Chí Dũng (2010) tiến hành phân tích vai trò của hệ thống tài chính đối với tăng trưởng kinh tế và phát triển bền vững thông qua việc nhấn mạnh vai trò đầu vào vốn trong các lý thuyết tăng trưởng. Ngoài ra, nghiên cứu cũng xem xét hệ thống tài chính trong nền kinh tế chuyển đổi và những hỗ trợ cho phát triển doanh nghiệp vừa và nhỏ. Nghiên cứu của nhóm tác giả cũng đã tiến hành khái quát các nghiên cứu liên quan ở nước ngoài, một kết luận chung là phát triển hệ thống tài chính có ý nghĩa tích cực đến tăng trưởng kinh tế.

Nghiên cứu của Nguyễn Đức Hùng và cộng sự (2013) được tiến hành với mục tiêu xác định nhân tố thúc đẩy phát triển hệ thống tài chính và kiểm định tự do kinh tế, tự do hóa tài khoản vốn hay tự do hóa thương mại có thúc đẩy phát triển hệ thống tài chính trong giai đoạn 19962012. Nghiên cứu sử dụng mô hình VECM, kết quả cho thấy độ mở thương mại ở Việt Nam chịu ảnh hưởng lớn của tự do hóa tài chính.

\section{QUÁ TRÌNH HộI NHẬP TÀI CHÍNH VÀ TĂNG TRƯỞNG KINH TẾ TẠI VIỆT NAM}

\subsection{Hội nhập tài chính ở Việt Nam}

Từ sau Đại hội Đảng lần thứ VI năm 1986, Việt Nam đã thay đổi cơ bản cơ chế quản lý kinh tế từ kế hoạch hóa tập trung sang cơ chế thị trường. Cùng với quá trình chuyển biến kinh tế này là sự thay đổi trong hệ thống tài chính, ngân hàng và tiền tệ của Việt Nam. Thể chế và hoạt động của thị trường tài chính ngày càng được cải thiện, thâm nhập sâu và rộng hơn vào hệ thống tài chính quốc tế. Để thúc đẩy quá trình hội nhập tài chính cần thiết phải thực hiện tự do hóa tài chính. Nghiên cứu của Viện Nghiên cứu Quản lý Kinh tế Trung ương (CIEM) xem xét quá trình tự do hóa tài chính của Việt Nam cho thấy:

Thứ nhất, theo chiều dọc, tự do hóa tài chính tại Việt Nam được bắt đầu vào những năm cuối thập kỷ 90 của thế kỷ XX, đánh dấu bằng việc ban hành Pháp lệnh Ngân hàng Nhà nước và Pháp lệnh về Ngân hàng, Hợp tác xã tín dụng và Công ty tài chính năm 1990, chuyển đổi mô hình hoạt động của hệ thống ngân hàng từ 1 cấp sang 2 cấp. Về mặt pháp lý, hệ thống pháp luật về hoạt động ngân hàng được bổ sung, hoàn thiện bằng việc ban hành Luật Ngân hàng Nhà nước và Luật các Tổ chức tín dụng năm 1997. Quá trình cải cách pháp luật và thể chế 
trên đã tạo sự chuyển biến cho thị trường tài chính. Chính sách tiền tệ được đổi mới căn bản, tăng cường sử dụng công cụ gián tiếp. Cơ chế điều hành lãi suất cũng được thay đổi, từ cơ chế lãi suất trần - sàn, sang cơ chế trần và cuối cùng chuyển sang lãi suất thỏa thuận. Nhà nước nới lỏng cơ chế quản lý tỷ giá, từ tỷ giá cố định sang tỷ giá có điều chỉnh. Quản lý ngoại hối dần được tự do, tăng tính tự chủ cho doanh nghiệp, người dân trong giao dịch ngoại hối. Bắt đầu từ tháng 12/2005, giao dịch vãng lai được tự do hóa hoàn toàn, Pháp lệnh ngoại hối được ban hành giúp cho hoạt động giao dịch được quy định rõ ràng, thông thoáng hơn. Chính sách tín dụng được thay đổi, từ cấp tín dụng cho khu vực quốc doanh sang đa dạng hóa thành phần được cấp tín dụng. Hệ thống thanh toán được hình thành, nâng cấp liên tục để phục vụ cho nền kinh tế.

Thứ hai, theo chiều ngang, Đại hội IX của Đảng năm 2001, coi khu vực có vốn đầu tư nước ngoài là một trong 6 thành phần kinh tế chính thức của Việt Nam, đánh dấu giai đoạn thực hiện chính sách mở cửa. Đặc biệt, sau khi Việt Nam trở thành thành viên chính thức của Tổ chức thương mại thế giới WTO, Việt Nam đón nhận dòng vốn rất lớn nước ngoài “chảy” vào. Hàng loạt Quỹ đầu tư nước ngoài, ngân hàng có vốn đầu tư nước ngoài hoặc $100 \%$ vốn nước ngoài được thành lập. Tính đến thời điểm 30/06/2015, theo thống kê của Ngân hàng Nhà nước, Việt Nam có 04 ngân hàng liên doanh với tổng vốn điều lệ gần 10.000 tỷ đồng, 05 ngân hàng $100 \%$ vốn nước ngoài với tổng vốn điều lệ hơn 20.000 tỷ đồng và 49 chi nhánh ngân hàng nước ngoài tại Việt Nam. Bên cạnh đó, Luật Đầu tư nước ngoài đã có tác dụng khơi thông dòng vốn, Việt Nam đón luồng vốn đầu tư FDI rất lớn vào Việt Nam. Theo số liệu Cục Đầu tư nước ngoài, tính đến cuối năm 2014, Việt Nam có 17.768 dự án đầu tư với tổng giá trị đăng ký 252.715 tỷ đồng. Dòng vốn FDI này có ý nghĩa quan trọng trong việc gia tăng nguồn vốn, tạo sự chuyển dịch cơ cấu kinh tế, chuyển giao công nghệ, giải quyết việc làm và thúc đẩy tăng trưởng kinh tế. Khu vực đầu tư nước ngoài ngày càng thể hiện vai trò, vị thế của mình, nếu năm 2000, đóng góp 5,2\% vào ngân sách nhà nước, thì đến năm 2014 đã tăng lên 14,3\% (Phạm Thanh Thảo, 2015).

\subsection{Tăng trưởng kinh tế ở Việt Nam}

Theo số liệu thống kê của IFS, kể khi thực hiện chính sách đổi mới nền kinh tế đất nước, Việt Nam đã đạt được nhiều thành tựu đáng kể trong tăng trưởng kinh tế. Thu nhập bình quân đầu người năm 1995 của Việt Nam chỉ là 288 đôla Mỹ (USD), đã tăng lên 2.052 đôla Mỹ năm 2014. Đặc biệt, trong giai đoạn 2000 - 2008, GDP bình quân đầu người của Việt Nam có sự gia tăng mạnh mẽ, GDP bình quân năm 2000 là 433 USD, đến năm 2007 giá trị này là 1.165 USD, tăng gấp 2,5 lần. 


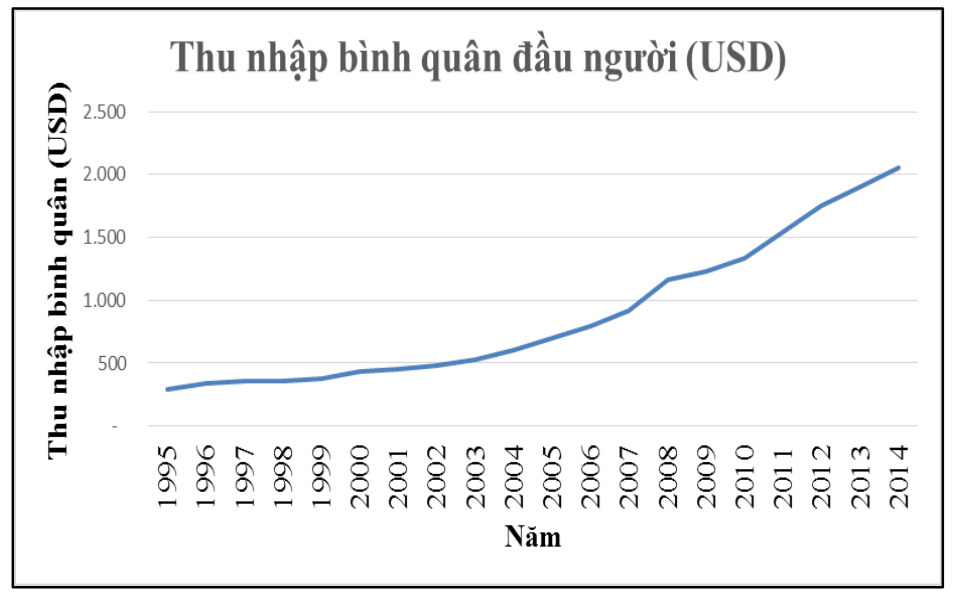

Nguồn: International Financial Statistics (IFS)

Hình 1: Thu nhập bình quân đầu người của Việt Nam trong giai đoạn 1995 - 2014

\section{MÔ HÌNH VÀ KẾT QUẢ NGHIÊN CÚU}

\subsection{Mô hình nghiên cứu}

Nghiên cứu này sử dụng mô hình vectơ hiệu chỉnh sai số (Vector Error Correction Model: VECM) nhằm xác định tác động của hội nhập tài chính đến tăng trưởng kinh tế của Việt Nam trong giai đoạn 1995-2014. Mô hình này phù hợp trong việc nghiên cứu ảnh hưởng của hội nhập tài chính đến tăng trưởng kinh tế cả trong dài hạn lẫn ngắn hạn. Điều kiện để sử dụng mô hình này là chuỗi dữ liệu của các biến đưa vào mô hình không dừng, có cùng bậc sai phân và tồn tại các mối quan hệ đồng tích hợp giữa các biến nghiên cứu.

Mô hình VECM với $\mathrm{k}$ biến có dạng như sau:

$$
\Delta Y_{t}=A_{0}+A Y_{t-1}+A_{1} \Delta Y_{t-1}+A_{2} \Delta Y_{t-2}+\ldots+A_{p} \Delta Y_{t-p}+\varepsilon
$$

Trong đó: $\quad \mathrm{Y}_{\mathrm{t}}$ : vectơ $(\mathrm{k} \times 1)$ gồm $\mathrm{k}$ biến $\left(\mathrm{y}_{1 \mathrm{t}}, \mathrm{y}_{2 \mathrm{t}}, \ldots, \mathrm{y}_{\mathrm{kt}}\right)$

$\mathrm{A}_{0}: \operatorname{vectơ}(\mathrm{k} \times 1)$

$\mathrm{A}$ : ma trận $(\mathrm{k} \mathrm{x} \mathrm{k)}$ gồm các hệ số cho biết mối quan hệ dài hạn giữa các biến

$\mathrm{A}_{\mathrm{i}}$ : ma trận $\mathrm{k} \mathrm{x} \mathrm{k}$

Dựa vào lý thuyết về tăng trưởng kinh tế và ảnh hưởng của hội nhập tài chính đến tăng trưởng kinh tế cũng như kế thừa kết quả các nghiên cứu trước đây, trong nghiên cứu này, các biến được đưa vào mô hình gồm có: GDP bình quân đầu người (đại diện cho tăng trưởng kinh tế), đầu tư trực tiếp nước ngoài/GDP (đại diện cho mức độ hội nhập tài chính), độ mở thương mại, tín dụng cho khu vực tư nhân/GDP (đại diện cho phát triển tài chính), đầu tư cho nền kinh tế/GDP (đại diện cho chính sách kinh tế). Các biến này được lấy logarit cơ số tự nhiên.

\subsection{Số liệu sử dụng}

Số liệu sử dụng trong nghiên cứu này là số liệu theo năm trong giai đoạn 1995-2014, được lấy từ những nguồn sau :

- GDP bình quân đầu người, xuất khẩu/GDP, nhập khẩu/GDP, Đầu tư trực tiếp nước ngoài/GDP: Ngân hàng Thế giới (World Bank);

- Tín dụng cho khu vực tư nhân: Quỹ tiền tệ quốc tế (IMF);

- Đầu tư trong nền kinh tế/GDP: Tổng cục thống kê Việt Nam. 


\subsection{Kết quả nghiên cứu}

\subsubsection{Kiểm định tính dừng}

Các biến nghiên cứu được kiểm tra tính dừng bởi kiểm định Augmented Dickey-Fuller $(\mathrm{ADF})$. Các biến được đưa vào mô hình nghiên cứu bao gồm các biến không dừng và đều có sai phân bậc 1: GDP bình quân đầu người (GDPPERCA), đầu tư trực tiếp nước ngoài/GDP (NFDI), độ mở thương mại (TRADOP), tín dụng cho khu vực tư nhân/GDP (CLPRIV), đầu tư cho nền kinh tế/GDP (INVRATIO).

Bảng 1: Kiểm định tính dừng của các chuỗi dữ liệu

\begin{tabular}{|l|c|l|c|}
\hline & t Student & \multicolumn{1}{|c|}{ Sai phân bậc 1 } & t Student \\
\hline LGDPPERCA & 0.8918 & LGDPPERCA & $-3.4333^{* *}$ \\
\hline LNFDI & -2.6269 & LNFDI & $-3.1297^{* *}$ \\
\hline LTRADOP & -1.9552 & LTRADOP & $-4.5190^{* * *}$ \\
\hline LCLPRIV & -1.2014 & LCLPRIV & $-2.9116^{*}$ \\
\hline LINVRATIO & -1.3524 & LINVRATIO & $-4.2426^{* * *}$ \\
\hline Ghi chú $:{ }^{*}, * *, * * *$ & dừng ở mức ý nghĩa $10 \%, 5 \%, 1 \%$ & \\
\hline
\end{tabular}

(Nguồn: Kết quả xư lý số liệu bằng phần mềm Winrats)

\subsubsection{Kiểm định đồng tích hợp}

Nghiên cứu sử dụng phương pháp đồng tích hợp của Johensan nhằm xác định mối quan hệ dài hạn của 05 biến sau đây: GDPPERCA, NFDI, TRADOP, CLPRIV và INVRATIO với độ trễ là 1 . Kết quả kiểm định cho thấy tồn tại một mối quan hệ đồng tích hợp giữa các biến đưa vào trong mô hình (Bảng 2).

Bảng 2: Kiểm định đồng tích hợp

\begin{tabular}{|c|c|c|c|c|c|c|c|}
\hline $\mathrm{p}-\mathrm{r}$ & $\mathrm{r}$ & Eig, Value & Trace & Trace* & Frac95 & $\mathrm{p}$-Value & p-Value* \\
\hline 5 & 0 & 0.973 & 121.979 & 99.769 & 76.813 & 0.000 & 0.000 \\
\hline 4 & 1 & 0.830 & 53.405 & 46.150 & 53.945 & 0.056 & 0.212 \\
\hline 3 & 2 & 0.395 & 19.790 & 17.962 & 35.070 & 0.739 & 0.838 \\
\hline 2 & 3 & 0.311 & 10.235 & 9.699 & 20.164 & 0.623 & 0.673 \\
\hline 1 & 4 & 0.153 & 3.162 & 3.111 & 9.142 & 0.560 & 0.570 \\
\hline
\end{tabular}

(Nguồn: Kết quả xủ lý số liệu bằng phần mềm Winrats)

\subsubsection{Mối quan hệ dài hạn}

Mối quan hệ đồng tích hợp giữa các biến trong mô hình nghiên cứu chỉ ra rằng giữa các biến nghiên cứu có một mối quan hệ dài hạn. Kết quả về mối quan hệ này được trình bày ở Bảng 3 . Trong dài hạn, đầu tư hội nhập tài chính (đại diện bởi biến Đầu tư trực tiếp nước ngoài/GDP) tác động thuận chiều đến GDP bình quân đầu người. Tín dụng cho khu vực tư nhân cũng tác động thuận chiều đến GDP bình quân đầu người. Độ mở thương mại có hệ số dương nhưng lại không có ý nghĩa thống kê cho thấy độ mở thương mại không cải thiện GDP bình quân đầu người. Trái với kỳ vọng, tỷ số Tổng đầu tư trong nền kinh tế/GDP có hệ số âm và có ý nghĩa 
thống kê có thấy đầu tư trong nền kinh tế tác động nghịch chiều đến tăng trưởng. Điều này chứng tỏ đầu tư trong nền kinh tế chưa thực sự hiệu quả.

Bảng 3: Tác động của các biến đến tăng trưởng kinh tế trong dài hạn

\begin{tabular}{|l|l|l|r|r|}
\hline \multicolumn{5}{|l|}{ Dependent Variable LGDPPERCA } \\
\hline \multicolumn{1}{|c|}{ Variable } & \multicolumn{1}{c|}{ Coeff } & \multicolumn{1}{l|}{ Std Error } & \multicolumn{1}{c|}{ T-Stat } & \multicolumn{1}{c|}{ Signif } \\
\hline Constant & 2.330750329 & 0.509108616 & 4.57810 & 0.00036239 \\
\hline LNFDI & 0.159243734 & 0.025455440 & 6.25578 & 0.00001539 \\
\hline LTRADOP & 0.248365963 & 0.173045048 & 1.43527 & 0.17173405 \\
\hline LCLPRIV & 0.394606552 & 0.026323055 & 14.99091 & 0.00000000 \\
\hline LINVRATIO & -0.659414450 & 0.080850878 & -8.15593 & 0.00000068 \\
\hline
\end{tabular}

(Nguồn: Kết quả xử lý số liệu bằng phần mềm Winrats)

\subsubsection{Kết quả mô hình VECM}

Kết quả của mô hình VECM sẽ cho biết tác động giữa các biến trong ngắn hạn. Do nghiên cứu này tập trung vào tác động của các biến đến tăng trưởng kinh tế trong ngắn hạn, vì vậy, nhóm tác giả chỉ trình bày phương trình liên quan (Bảng 4).

Bảng 4: Tác động của các biến đến tăng trưởng kinh tế trong ngắn hạn

\begin{tabular}{|l|r|r|r|l|}
\hline Dependent Variable DLGDPPERCA \\
\hline Variable & \multicolumn{1}{|c|}{ Coeff } & \multicolumn{1}{l|}{ Std Error } & \multicolumn{1}{c|}{ T-Stat } & \multicolumn{1}{c|}{ Signif } \\
\hline DLGDPPERCA $\{1\}$ & -0.291083394 & 0.261065474 & -1.11498 & 0.28862517 \\
\hline DLNFDI $\{1\}$ & 0.153894234 & 0.060305870 & 2.55189 & 0.02690417 \\
\hline DLTRADOP $\{1\}$ & 0.184285691 & 0.160758124 & 1.14635 & 0.27597404 \\
\hline DLCLPRIV $\{1\}$ & 0.390069517 & 0.161436693 & 2.41624 & 0.03423421 \\
\hline DLINVRATIO $\{1\}$ & -0.406287768 & 0.230036063 & -1.76619 & 0.10506431 \\
\hline Constant & 0.030666271 & 0.038239486 & 0.80195 & 0.43956156 \\
\hline ECM $\{1\}$ & -0.043740066 & 0.344087037 & -0.12712 & 0.90114005 \\
\hline
\end{tabular}

(Nguồn: Kết quả xư lý số liệu bằng phần mềm Winrats)

Kết quả ở Bảng 4 cho thấy trong ngắn hạn, hội nhập tài chính tác động thuận chiều đến tăng trưởng kinh tế. Tương tự, tín dụng cho khu vực tư nhân cũng tác động thuận chiều đến tăng trưởng kinh tế trong ngắn hạn. Các biến còn lại không có tác động đến tăng trưởng kinh tế. Hệ số điều chỉnh ECM mang dấu âm nhưng lại không có ý nghĩa thống kê chứng tỏ nền kinh tế sẽ cần rất nhiều thời gian để quay trở lại trạng thái cân bằng dài hạn một khi bị chệch khỏi trạng thái này.

\section{KẾT LUẬN VÀ MỘT SỐ KHUYẾN NGHỊ CHÍNH SÁCH}

Bài báo này sử dụng mô hình vectơ hiệu chỉnh sai số (VECM) để nghiên cứu tác động trong ngắn hạn và dài hạn của hội nhập tài chính đến tăng trưởng kinh tế của Việt Nam giai đoạn 1995-2014. Các biến sử dụng trong mô hình bao gồm GDP bình quân đầu người (đại diện cho tăng trưởng kinh tế), đầu tư trực tiếp nước ngoài/GDP (đại diện cho hội nhập tài chính), độ mở thương mại, đầu tư trong nền kinh tế/GDP và Tín dụng cho khu vực tư nhân. 
Kết quả nghiên cứu chỉ ra rằng hội nhập tài chính tác động tích cực đến tăng trưởng kinh tế cả trong ngắn hạn và dài hạn. Tương tự, tín dụng cho khu vực tư nhân cũng tác động thuận chiều đến tăng trưởng kinh tế cả trong dài hạn và ngắn hạn. Đầu tư trong nền kinh tế/GDP chỉ tác động đến tăng trưởng kinh tế trong dài hạn nhưng lại tác dộng nghịch chiều trong khi độ mở thương mại không tác động đến tăng trưởng kinh tế cả trong ngắn hạn lẫn dài hạn.

Kết quả trên cho thấy hội nhập tài chính thúc đẩy sự phát triển kinh tế, góp phần xóa đói giảm nghèo tại Việt Nam trong giai đoạn 1995-2014. Điều này chứng tỏ Chính phủ Việt Nam đã có những chính sách khá phù hợp và tận dụng được những lợi ích mà hội nhập tài chính mang lại. Từ kết quả nghiên cứu được tìm thấy, chúng tôi đưa ra một số khuyến nghị chính sách như sau: Trước hết, Chính phủ cần có nhiều chính sách ưu đãi cho các nhà đầu tư nước ngoài khi đầu tư vào Việt Nam nhằm thu hút nguồn vốn FDI. Bên cạnh đó, Chính phủ cũng cần tạo điều kiện cho khu vực kinh tế tư nhân tiếp cận được nguồn vốn vay. Ngoài ra, Chính phủ cần áp dụng các chính sách nhằm nâng cao hiệu quả đầu tư trong nền kinh tế. Bên cạnh mặt tích cực, hội nhập tài chính sẽ dẫn đến sự bất ổn của nền kinh tế vĩ mô (Mougani (2012)). Do đó, một vấn đề rất quan trọng là Chính phủ cần áp dụng các chính sách nhằm củng cố và phát triển hệ thống tài chính - ngân hàng, đảm bảo an ninh tài chính khi quá trình hội nhập tài chính của Việt Nam ngày càng sâu rộng với khu vực và thế giới.

\section{TÀI LIỆU THAM KHẢO}

\section{Tiếng Việt}

1. Cổng thông tin điện tử Cục Đầu tư nước ngoài (2015), Tình hình đầu tu nước ngoài năm 2014, truy cập ngày 10/08/2015 tại địa chỉ http://fia.mpi.gov.vn/tinbai/3206/Tinhhinh-dau-tu-nuoc-ngoai-nam-2014.

2. Vương Quân Hoàng, Trần Chí Dũng (2011), Hệ thống tài chính và phát triển bền vũng, Kỷ yếu Hội thảo Triển vọng kinh tế thế giới và Chính sách ứng phó của Việt Nam, Ủy ban Giám sát Tài chính Quốc gia.

3. Nguyễn Đức Hùng, Nguyễn Thanh Tùng, Dương Lê Huyền Trang (2013), Tụ do hóa kinh tế với phát triển tài chính trong nền kinh tế chuyển đổi: Truờng hợp Việt Nam giai đoạn 1996 - 2012, Seminar Nghiên cứu Kinh tế và Chính sách.

4. Nguyễn Xuân Thành (2013), Tư do hóa tài chính, Bài đọc Tài chính phát triển, Chương trình Giảng dạy Kinh tế Fulbright.

5. Ngân hàng Thế giới (1997), Các dòng vốn tu nhân đến các quốc gia đang phát triểnCon đường hội nhập tài chính, Nhà xuất bản Đại học Oxford.

6. Pincus, J. (2010), Tư do hóa tài chính và tăng trưởng, Bài đọc Kinh tế vĩ mô, Chương trình Giảng dạy Kinh tế Fulbright. 
7. Pincus, J. (2012), Tăng trương trong dài hạn, Bài đọc Kinh tế vĩ mô, Chương trình Giảng dạy Kinh tế Fulbright.

8. Viện Nghiên cứu Quản lý Kinh tế Trung ương (CIEM), "Tư do hóa tài chính ở Việt Nam - Con đường và bước đi”.

\section{Tiếng Anh}

1. Chaudhry, I. S. (2007), Financial Liberalization and Macroeconomic Performance: Empirical Evidence from Pakistan, Pakistan Journal of Social Sciences (PJSS), 33, pp. 227-241.

2. Edison, H.J. , Levine R., Ricci L., Slok T., (2002), International Financial Integration and Economic Growth, Journal of International Money and Finance, Elsevier, 21(6), pp 749-776.

3. Jahfer A., and Inoue, T. (2014), Financial Development and Economic Growth: The Role of Stock Market in Japan, International Review of Business Research Papers, 10, pp 46-61.

4. King, R. and Levine, R. (1993), Finance and Growth: Schumpeter Might be Right, Quarterly Journal of Economics, 108, pp. 717-737.

5. Mougani, G. (2012), An Analysis of the Impact of Financial Integration on Economic Activity and Macroeconomic Volatility in Africa within the Financial Globalization Context, Working Paper, African Development Bank Group.

6. Evans, O. (2013), Growth Effects of Financial Integration and Financial Deepening in Selected Sub-Saharan African Economies: a Panel-Data Approach, MPRA Paper No. 52458, posted 25. December 2013.

7. Onwumere, J.U.J. (2012), The Impact of Interest Rate Liberalization on Savings and Investment: Evidence from Nigeria, Research Journal of Finance and Accounting, 3, pp. 130-136.

8. Prasad E., et al (2007), Effects of Financial Globalization on Developing Countries: Some Empirical Evidence, IMF.

9. Von Furstenberg, G.M. (1998), From Worldwide Capital Mobility to International Financial Integration: A ReviewEssay, Open Economies Review, vol. 9, pp. 53-89. 